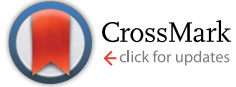

Cite this: Chem. Sci., 2016, 7, 2679

Received 3rd November 2015 Accepted 9th January 2016

DOI: $10.1039 / c 5 s c 04169 d$

www.rsc.org/chemicalscience

\section{A visible-light-promoted radical reaction system for azidation and halogenation of tertiary aliphatic $\mathrm{C}-\mathrm{H}$ bonds $\uparrow$}

\author{
Yaxin Wang, ${ }^{a}$ Guo-Xing Li, ${ }^{a}$ Guohui Yang, ${ }^{a}$ Gang $\mathrm{He}^{\mathrm{a}}$ and Gong Chen ${ }^{\text {*ab }}$ \\ A highly tunable radical-mediated reaction system for the functionalization of tertiary aliphatic $\mathrm{C}-\mathrm{H}$ bonds \\ was developed. Reactions of various substrates with the Zhdankin azidoiodane reagent $1, \mathrm{Ru}(\mathrm{bpy})_{3} \mathrm{Cl}_{2}$, and \\ visible light irradiation at room temperature gave $\mathrm{C}-\mathrm{H}$ azidated or halogenated products in an easily \\ controllable fashion. These reactions are efficient, selective, and compatible with complex substrates. \\ They provide a potentially valuable tool for selectively labeling tertiary $\mathrm{C}-\mathrm{H}$ bonds of organic and \\ biomolecules with tags of varied chemical and biophysical properties for comparative functional studies.
}

\section{Introduction}

$\mathrm{C}-\mathrm{H}$ bonds are the most prevalent chemical bonds on the surface of organic and biomolecules. Better means for the selective and controllable functionalization of $\mathrm{C}-\mathrm{H}$ bonds could greatly facilitate a broad range of applications such as tagging organic and biomolecules, drug development and mapping ligand-receptor interactions., ${ }^{\mathbf{1 , 2}}$ Despite their tremendous potential, the low reactivity of $\mathrm{C}-\mathrm{H}$ bonds and the difficulty of achieving selectivity pose a significant challenge for the realization of a $\mathrm{C}-\mathrm{H}$ labeling strategy, especially for more inert aliphatic $\mathrm{C}-\mathrm{H}$ bonds. Radical reactions could provide a simple yet powerful approach to selectively target specific aliphatic $\mathrm{C}-\mathrm{H}$ bonds due to their inherent ability to differentiate aliphatic $\mathrm{C}-\mathrm{H}$ bonds based on the bond dissociation energy. ${ }^{3-5}$ While various radical aliphatic $\mathrm{C}-\mathrm{H}$ functionalization reactions have been well-studied, new methods with better reactivity, versatility and biocompatibility are necessary for the selective and efficient $\mathrm{C}-\mathrm{H}$ labeling of complex substrates.

Among reported aliphatic $\mathrm{C}-\mathrm{H}$ functionalization reactions, $\mathrm{C}-\mathrm{H}$ azidation has proven to be particularly useful due to the unique photophysical and chemical reactivity of the azido group. ${ }^{6-14}$ In 1996, Zhdankin ${ }^{8}$ reported that the reaction of simple hydrocarbons with azidoiodane $\mathbf{1}$ in the presence of benzoyl peroxide led to the selective azidation of $3^{\circ}$ and activated $2^{\circ} \mathrm{C}-\mathrm{H}$ bonds in moderate to good yield. ${ }^{9-11}$ Hartwig recently discovered that $\mathrm{Fe} / \mathrm{PyBOX}$ catalysts promote aliphatic

${ }^{a}$ State Key Laboratory and Institute of Elemento-Organic Chemistry, Collaborative Innovation Center of Chemical Science and Engineering (Tianjin), Nankai University, Tianjin 300071, China.E-mail: gongchen@nankai.edu.cn

${ }^{b}$ Department of Chemistry, The Pennsylvania State University, 104 Chemistry Building, University Park, PA 16802, USA. E-mail: guc11@psu.edu

$\dagger$ Electronic supplementary information (ESI) available. See DOI: $10.1039 / \mathrm{c} 5 \mathrm{sc} 04169 \mathrm{~d}$
$\mathrm{C}-\mathrm{H}$ azidation with $\mathbf{1}$ under milder conditions, allowing the labeling of complex natural products with high selectivity. ${ }^{\mathbf{1 2 , 1 3}}$ Herein, we report a new strategy to affect the azidation of $3^{\circ} \mathrm{C}-\mathrm{H}$ bonds of complex substrates using the Zhdankin reagent $\mathbf{1}$, a photosensitizer and visible-light irradiation at room temperature (Scheme 1). Furthermore, this visible-light-promoted radical reaction system can be conveniently modulated by the addition of nucleophilic halides to achieve aliphatic $\mathrm{C}-\mathrm{H}$ chlorination and bromination with high efficiency and chemospecificity.

\section{Results and discussion}

Our research in radical $\mathrm{C}-\mathrm{H}$ functionalization chemistry stems from our interest in the synthetic and biological studies of peptides. ${ }^{15}$ Compared with $\alpha$-amino acid ( $\alpha \mathrm{AA}$ ) residues bearing polar or aromatic side chains, the structural and functional roles of hydrophobic aliphatic $\alpha$ AA residues such as leucine and

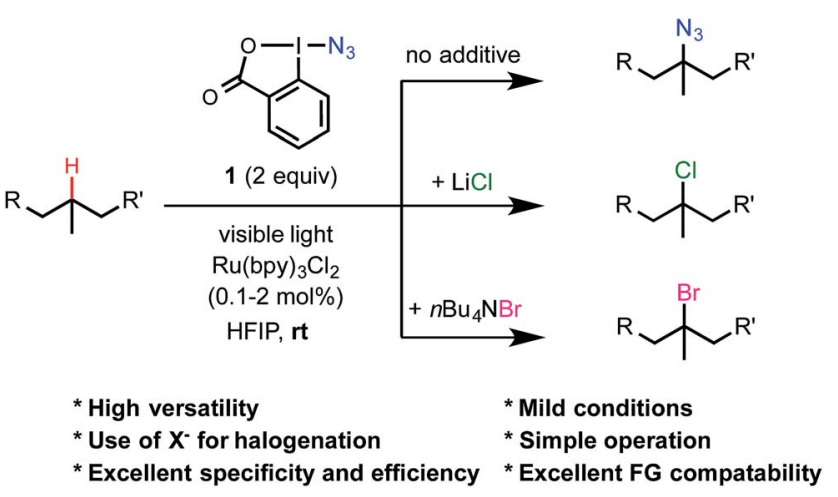

Scheme 1 A highly tunable radical-mediated reaction system for the selective functionalization of $3^{\circ} \mathrm{C}\left(\mathrm{sp}^{3}\right)-\mathrm{H}$ bonds under the promotion of visible light. 
valine in peptides and proteins are much more difficult to probe due to the lack of suitable chemical handles in these residues. Following the report of Hartwig's Fe-catalyzed aliphatic $\mathrm{C}-\mathrm{H}$ azidation, ${ }^{12}$ we wondered whether this azidation chemistry could potentially provide a long sought-after method for selectively labeling the aliphatic $\alpha \mathrm{AA}$ residues of peptides and proteins. As shown in Table 1, we commenced our investigation with the azidation of $N$-phthaloyl leucine methyl ester 2 with 1 under various reported conditions (Table 1). The reaction of 2 under Fe/iPr-PyBOX-catalyzed conditions in $\mathrm{CH}_{3} \mathrm{CN}$ provided the desired azidated product 3 in low yield (entry 1 ). The reaction under benzoyl peroxide-promoted conditions also gave 3 in moderate yield (entry 4). Interestingly, the azidation of Leu 2 proceeded in good yield without any catalyst or additive at $80^{\circ} \mathrm{C}$ in hexafluoroisopropanol (HFIP) under an air atmosphere, forming ortho-iodobenzoic acid as the main byproduct (entry 9).

In order to achieve better biocompatibility, we next investigated whether the azidation reaction could proceed at room temperature. While the use of various electron transfer reagents such as zinc metal and cerium ammonium nitrate failed, we were delighted to find that the application of a photosensitizer $\left(\mathrm{Ru}(\mathrm{bpy}){ }_{3} \mathrm{Cl}_{2}\right)$ and visible light irradiation (VL: $12 \mathrm{~W}$ household fluorescent light bulb) formed 3 in moderate yield under an $\mathrm{Ar}$ atmosphere (entry 11). ${ }^{16}$ Interestingly, the use of $0.1 \mathrm{~mol} \%$ of $\mathrm{Ru}(\mathrm{bpy})_{3} \mathrm{Cl}_{2}$ gave significantly improved results than when using $5 \mathrm{~mol} \%$ of $\mathrm{Ru}\left(\right.$ bpy) ${ }_{3} \mathrm{Cl}_{2}$ (entry 12). Furthermore, we were surprised to find that the use of $20 \mathrm{~mol} \%$ of $\mathrm{Ru}(\mathrm{bpy})_{3} \mathrm{Cl}_{2}$ produced only a small amount of 3 but instead produced a $35 \%$ yield of chlorinated product $\mathbf{4}$ (entry 14). This result prompted us to evaluate different $\mathrm{Cl}$ donors to improve the yield of the chlorinated product (see ESI $\dagger$ for more screening results). A number of nucleophilic $\mathrm{Cl}$ sources worked, $\mathrm{LiCl}$ or TMSCl gave 4 in the highest yield and selectivity (entries 16 and 17). The addition of 2 equiv. of TEMPO shut down the reaction with little conversion of 2 (entry 19). The reaction in darkness gave little product (entry 20). Interestingly, visible light irradiation in the absence of $\mathrm{Ru}(\mathrm{bpy})_{3} \mathrm{Cl}_{2}$ also gave a small amount of 3 (entry 21).

As shown in Scheme 2, $\mathrm{C}-\mathrm{H}$ azidation reactions with azidoiodane 1 worked well for a variety of aliphatic substrates with excellent $3^{\circ} \mathrm{C}-\mathrm{H}$ selectivity under the optimized light-promoted conditions A. ${ }^{17}$ Common functional groups e.g. Boc, Bn, TBS, ester and amide were well tolerated. Steric hindrance and electron-withdrawing functional groups generally diminish the reactivity of the neighbouring $\mathrm{C}-\mathrm{H}$ bonds, allowing preferential labeling of certain $3^{\circ} \mathrm{C}-\mathrm{H}$ bonds of complex substrates. ${ }^{1 \boldsymbol{1}, \boldsymbol{e}}$ For instance, azidation selectively took place at the more distal $3^{\circ}$

Table $1 \quad 3^{\circ} \mathrm{C}-\mathrm{H}$ azidation and chlorination of Leu 2

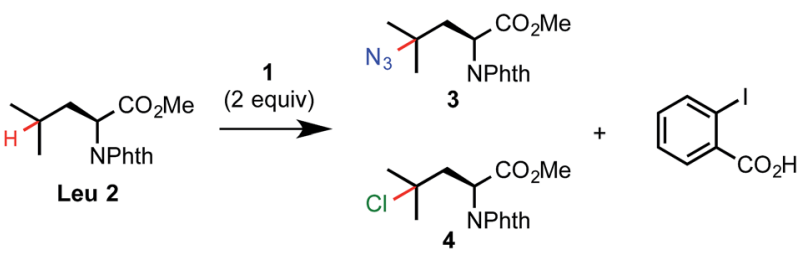

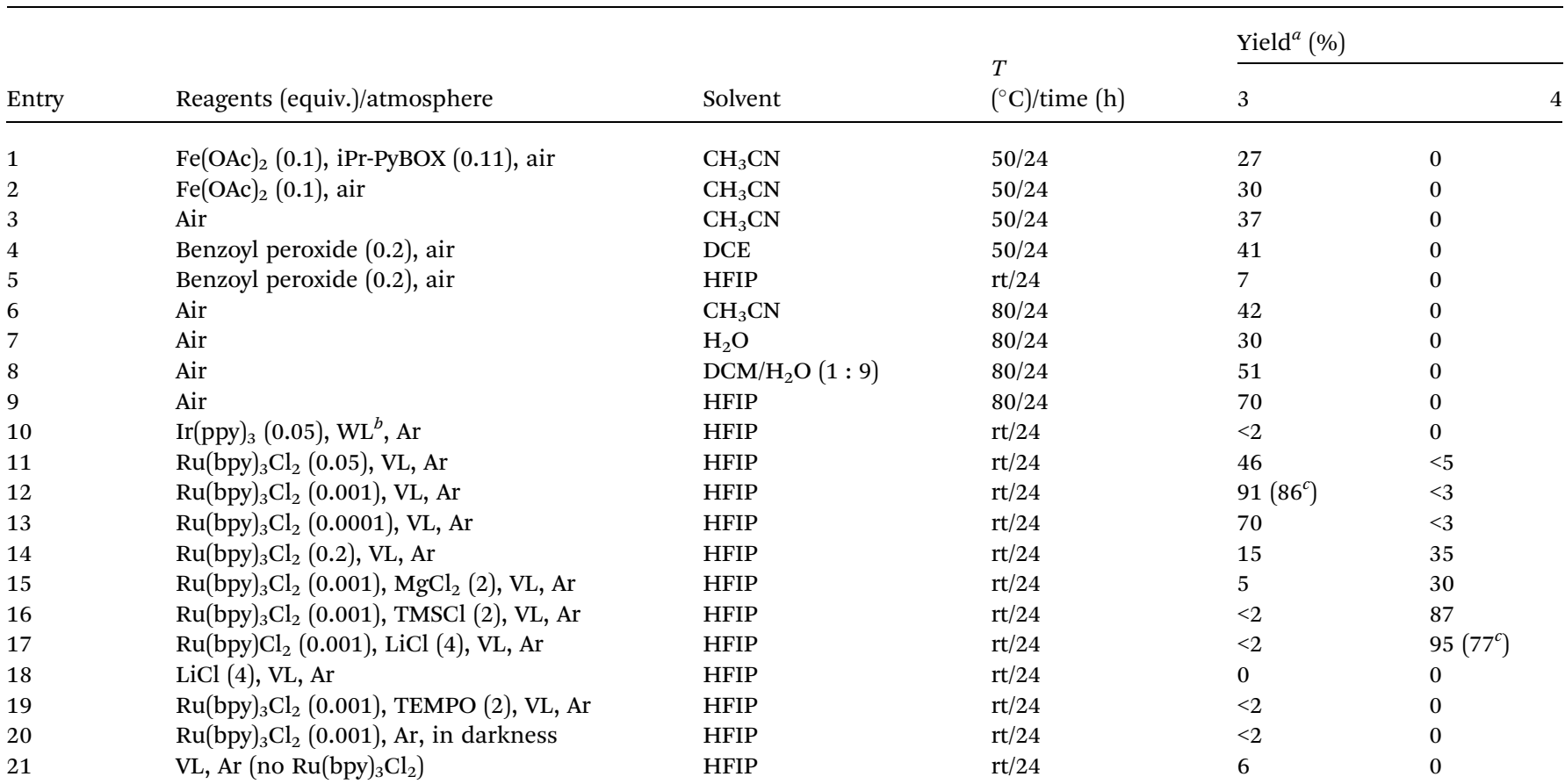

${ }^{a}$ Yields are based on ${ }^{1} \mathrm{H}$-NMR analysis on a $0.2 \mathrm{mmol}$ scale. ${ }^{b}$ VL: $12 \mathrm{~W}$ fluorescent bulb. ${ }^{c}$ Isolated yield (see ESI). 


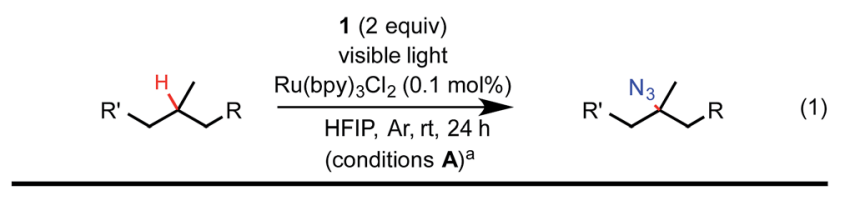

$$
\begin{aligned}
& \mathrm{N}_{3} \Upsilon_{\mathrm{NPhth}} \\
& \text { 5, } 35 \% \\
& \mathrm{~N}_{3} \Upsilon^{N P h t h} \\
& \text { 6, } 80 \%\left(95 \%^{b}\right)
\end{aligned}
$$

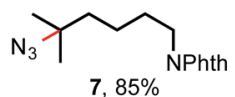

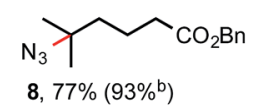
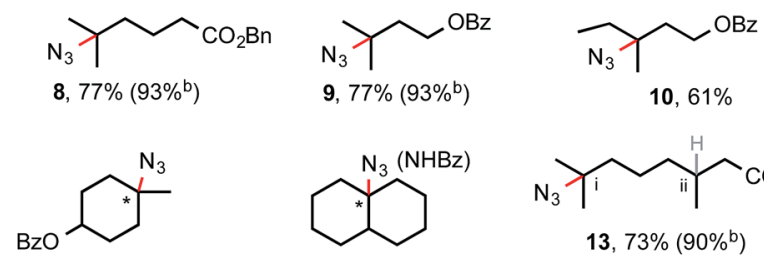

11, $80 \%$ (dr: 1:1)

$12,52 \%^{\mathrm{C}}(\mathrm{dr}: \sim 1.3: 1)$

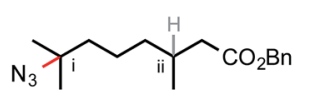

$13,73 \%\left(90 \%{ }^{\mathrm{b}}\right)$

( $\mathrm{C}_{\mathrm{ii}}$-azidated product $\left.<3 \%\right)$

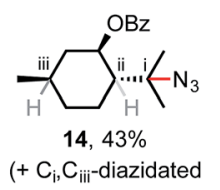

$14 d, 18 \%)$

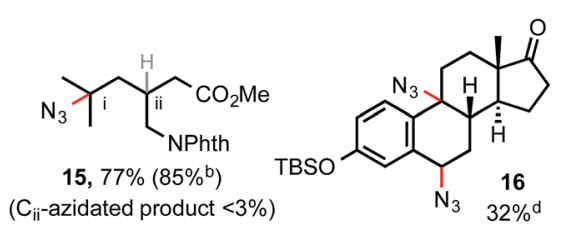

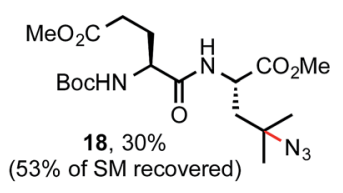

Scheme 2 Substrate scope of aliphatic $\mathrm{C}-\mathrm{H}$ azidation. [a] Isolated yield on a $0.2 \mathrm{mmol}$ scale. [b] ${ }^{1} \mathrm{H}-\mathrm{NMR}$ yield. Isolated yield was occasionally compromised by the volatility of the product and/or difficulties in purification. [c] Isolated yield of its amide derivative (see ESI $\dagger$ ). [d] As the only major product.

carbon of 13 and $N$-phthaloyl pregabalin methyl ester 15. Moreover, we were delighted to find that the $\mathrm{C}-\mathrm{H}$ azidation of dipeptides under the standard light-promoted conditions also provided good yield and excellent selectivity (see 17 and 18).

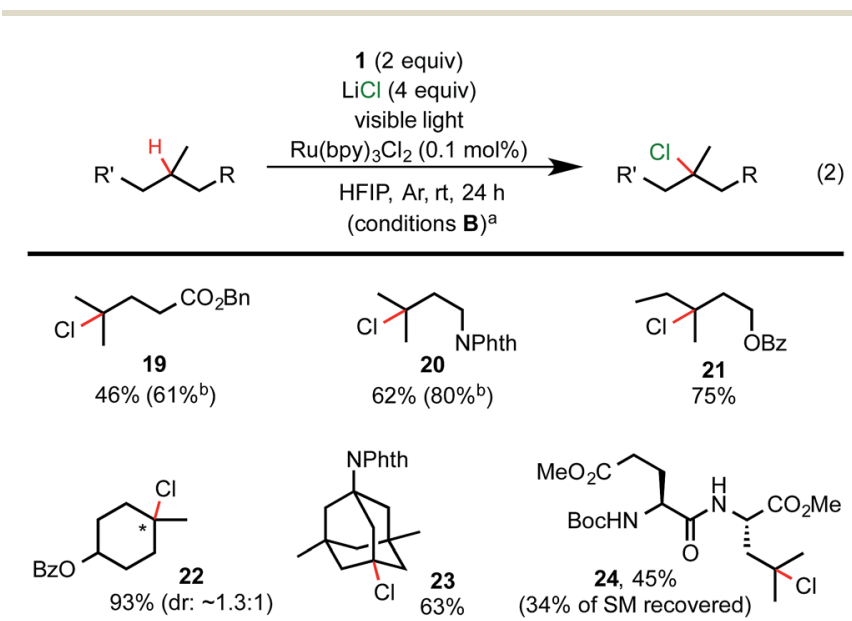

Scheme 3 Substrate scope of $\mathrm{C}-\mathrm{H}$ chlorination. (a) Isolated yield on a $0.2 \mathrm{mmol}$ scale and (b) ${ }^{1} \mathrm{H}-\mathrm{NMR}$ yield.
As shown in Scheme 3, visible light-promoted $3^{\circ} \mathrm{C}-\mathrm{H}$ chlorination reactions with azidoiodane $\mathbf{1}$ and $\mathrm{LiCl}$ as the $\mathrm{Cl}$ donor also demonstrated excellent efficiency, site-selectivity and functional group tolerance. ${ }^{18}$ The reactivity of these C-H chlorination reactions was slightly higher than the corresponding azidation reaction (see $21 v s$. 10 and $24 v s$. 18). Additionally, we were pleased to find that this reaction system can be further modulated to form $3^{\circ} \mathrm{C}-\mathrm{H}$ brominated products by the addition of a bromide donor. ${ }^{19,20}$ As shown in Scheme 4, the reaction of various aliphatic substrates with 2 equiv. of $n \mathrm{Bu}_{4} \mathrm{NBr}, 2$ equiv. of 1 , and $2 \mathrm{~mol} \%$ of $\mathrm{Ru}(\mathrm{bpy})_{3} \mathrm{Cl}_{2}$ under visible light irradiation (conditions C) gave $3^{\circ} \mathrm{C}-\mathrm{H}$ brominated products in good yield and with excellent selectivity. It is worth noting that the competing $\mathrm{C}-\mathrm{H}$ azidation process was completely suppressed in both chlorination and bromination reaction systems.

The azidation reactions under the newly developed conditions are consistent with the radical chain mechanisms proposed by Zhdankin ${ }^{8}$ (Scheme $5 \mathrm{~A}$ ). The radical chain mechanism is supported by the large quantum yield $(\Phi \sim 18$, measured by Yoon's method ${ }^{21}$ ) of the $\mathrm{C}-\mathrm{H}$ azidation reaction of 32 with 1 (see ESI†). Under thermally promoted conditions (see entry 9 , Table 1 ), the weak $\mathrm{I}-\mathrm{N}_{3}$ bond of $\mathbf{1}$ presumably undergoes homolytic cleavage to form an iodanyl radical $\mathbf{I}$ and an azido radical. $^{8}$ Because of the relative weak reactivity the of $\mathrm{N}_{3}$ radical, ${ }^{22} \mathrm{I}$ likely serves as the $\mathrm{H}$ abstractor ${ }^{23}$ to convert the $\mathrm{C}-\mathrm{H}$ substrate to a C-centered radical intermediate II. II then attacks 1 to form the azidated product and regenerates I, which propagates the radical chain reaction. Under visible-light irradiation in the presence of $\mathrm{Ru}(\mathrm{bpy})_{3} \mathrm{Cl}_{2}, \mathbf{1}$ may be activated by electron transfer $^{24}$ to generate radical I, which can trigger the same chain reaction at rt. The chlorination reactions likely share the same mechanism for the azidoiodane-mediated radical initiation step (formation of $\mathbf{I}$ ) as the azidation reactions. However, chloroiodane $31^{25}$ formed via in situ substitution of $\mathbf{1}$ with $\mathrm{Cl}^{-}$ probably overrides azidoiodane in the subsequent chain propagation step to selectively form the $\mathrm{C}-\mathrm{H}$ chlorinated products (Scheme 5B). Our control experiments indicated that both $\mathbf{1}$ and 31 are involved in the chlorination reaction. As shown in eqn 4 , mixing of $\mathbf{1}$ and LiCl in HFIP at rt in the absence of light can

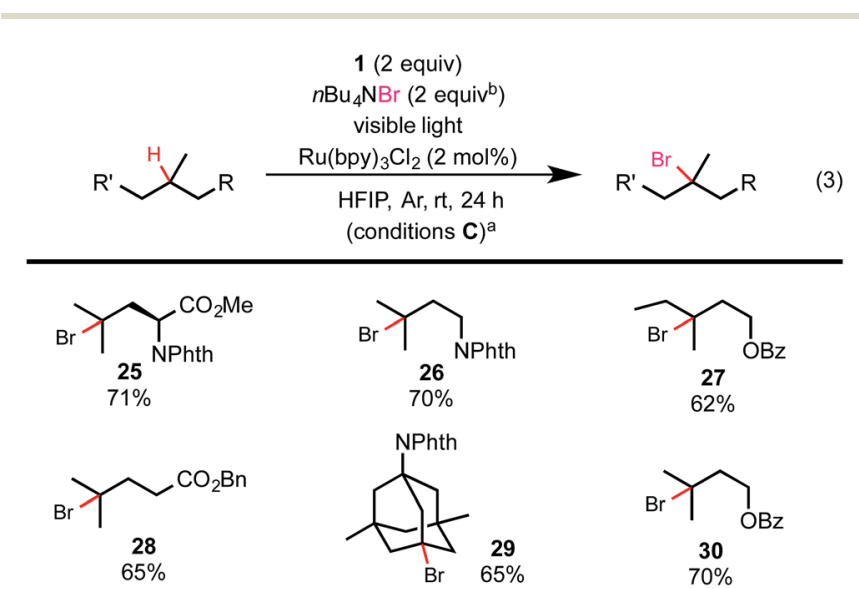

Scheme 4 Substrate scope of $\mathrm{C}-\mathrm{H}$ bromination. (a) Isolated yield on a $0.2 \mathrm{mmol}$ scale; (b) added in 2 portions ( $1+1$ equiv.). 
A) C-H azidation with 1 based on Zhdankin's proposal

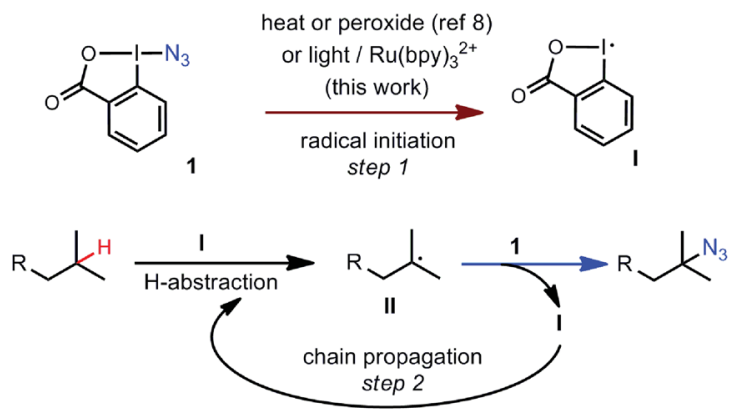

B) Light-promoted $\mathrm{C}-\mathrm{H}$ chlorination with 1 and $\mathrm{Cl}^{-}$

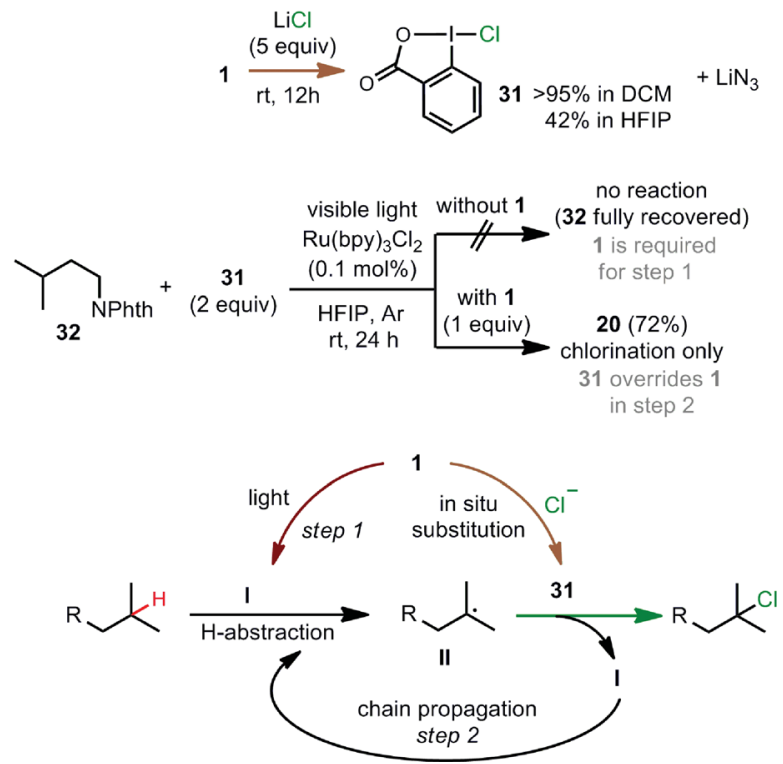

Scheme 5 Plausible mechanisms for $\mathrm{C}-\mathrm{H}$ azidation and chlorination.

form 31 (42\% yield in $12 \mathrm{~h}$ ). Subjecting substrate 32 and 2 equiv. of pre-made $\mathbf{3 1}$ to the standard light-promoted conditions did not give any reaction (eqn 5). Interestingly, the addition of 1 equiv. of 1 together with 31 cleanly restored the chlorination reaction (see more details in ESI $\dagger$ ). ${ }^{26}$ This suggests that chloride 31 cannot be directly activated to generate the iodanyl radical I for the initial $\mathrm{H}$-abstraction, but is more reactive than azidoiodane toward nucleophilic attack by the radical intermediate II. $\mathrm{C}-\mathrm{H}$ bromination with $n \mathrm{Bu}_{4} \mathrm{NBr}$ may follow a similar pathway as chlorination.

\section{Conclusions}

In summary, we have developed a uniquely tunable radicalmediated reaction system for the azidation and halogenation of tertiary aliphatic $\mathrm{C}-\mathrm{H}$ bonds of various substrates with azidoiodane $\mathbf{1}$ and visible light irradiation at room temperature. These reactions provide a simple and powerful method for selectively labeling tertiary aliphatic $\mathrm{C}-\mathrm{H}$ bonds of organic molecules with diverse tags. In addition to a mild protocol for radical aliphatic $\mathrm{C}-\mathrm{H}$ functionalization, this study demonstrated a novel strategy to use more easily available nucleophilic halide reagents for radical $\mathrm{C}-\mathrm{H}$ halogenation reactions. Further mechanistic studies and expansion of this reaction system to achieve other types of aliphatic $\mathrm{C}-\mathrm{H}$ functionalization and applications in labeling biomolecules are currently under investigation.

\section{Acknowledgements}

We gratefully thank the State Key Laboratory of ElementoOrganic Chemistry at Nankai University for financial support of this work.

\section{Notes and references}

1 For selected reviews on $\mathrm{C}-\mathrm{H}$ activation for organic synthesis and labeling: (a) K. Godula and D. Sames, Science, 2006, 312, 67; (b) T. Newhouse and P. S. Baran, Angew. Chem., Int. Ed., 2011, 50, 3362; (c) J. Yamaguchi, A. D. Yamaguchi and K. Itami, Angew. Chem., Int. Ed., 2012, 51, 8960; (d) J. Wencel-Delord and F. Glorius, Nat. Chem., 2013, 5, 369; (e) M. C. White, Science, 2012, 335, 807; (f) A. F. M. Noisier and M. A. Brimble, Chem. Rev., 2014, 114, 8775.

2 (a) E. M. Sletten and C. R. Bertozzi, Angew. Chem., Int. Ed., 2009, 48, 6974; (b) Y. Takaoka, A. Ojida and I. Hamachi, Angew. Chem., Int. Ed., 2013, 52, 4088.

3 For selected examples on aliphatic $\mathrm{C}-\mathrm{H}$ oxygenation, thiolation, and amination via non-organometallic mechanisms: (a) M. S. Chen and M. C. White, Science, 2007, 318, 783; (b) Q. Michaudel, D. Thevenet and P. S. Baran, J. Am. Chem. Soc., 2012, 134, 2547; (c) Y. Amaoka, S. Kamijo, T. Hoshikawa and M. Inoue, J. Org. Chem., 2012, 77, 9959; (d) N. D. Litvinas, B. H. Brodsky and J. Du Bois, Angew. Chem., Int. Ed., 2009, 48, 4513; (e) S. Guo, X. Zhang and P. Tang, Angew. Chem., Int. Ed., 2015, $54,4065$.

4 For selected examples on radical-mediated aliphatic $\mathrm{C}-\mathrm{H}$ fluorination: (a) J.-B. Xia, C. Zhu and C. Chen, J. Am. Chem. Soc., 2013, 135, 17494; (b) Y. Amaoka, M. Nagatomo and M. Inoue, Org. Lett., 2013, 15, 2160; (c) S. D. Halperin, H. Fan, S. Chang, R. E. Martin and R. Britton, Angew. Chem., Int. Ed., 2014, 53, 4690; (d) C. W. Kee, K. F. Chin, M. W. Wong and C.-H. Tan, Chem. Commun., 2014, 50, 8211. 5 For selected examples on enzyme-catalyzed aliphatic $\mathrm{C}-\mathrm{H}$ functionalization: (a) K. Zhang, B. M. Shafer, M. D. Demars, H. A. Stern and R. Fasan, J. Am. Chem. Soc., 2012, 134, 18695; (b) M. L. Matthews, W.-C. Chang, A. P. Layne, L. A. Miles, C. Krebs and J. M. Bollinger Jr, Nat. Chem. Biol., 2014, 10, 209.

6 (a) S. Brase, C. Gil, K. Knepper and V. Zimmermann, Angew. Chem., Int. Ed., 2005, 44, 5188; (b) W. Song, S. I. Kozhushkov and L. Ackermann, Angew. Chem., Int. Ed., 2013, 52, 6576.

7 For selected examples of $\mathrm{sp}^{2} \mathrm{C}-\mathrm{H}$ azidation reactions: $(a)$ Y. Kita, H. Tohma, M. Inagaki, K. Hatanaka and T. Yakura, Tetrahedron Lett., 1991, 32, 4321; (b) D. Lubriks, I. Sokolovs and E. Suna, J. Am. Chem. Soc., 2012, 134, 15436; (c) 
C. Tang and N. Jiao, J. Am. Chem. Soc., 2012, 134, 18924; (d) F. Xie, Z. Qi and X. Li, Angew. Chem., Int. Ed., 2013, 52, 11862. 8 V. V. Zhdankin, A. P. Krasutsky, C. J. Kuehl, A. J. Simonsen, J. K. Woodward, B. Mismash and J. T. Bolz, J. Am. Chem. Soc., 1996, 118, 5192.

9 For pioneering work on azidation with hypervalent iodine reagents: (a) P. Magnus, J. Lacour and W. Weber, J. Am. Chem. Soc., 1993, 115, 9347; (b) Y. Kita, H. Tohma, T. Takada, S. Mitoh, S. Fujita and M. Gyoten, Synlett, 1994, 427.

10 For selected examples on radical aliphatic $\mathrm{C}-\mathrm{H}$ functionalization with hypervalent iodine(III) reagents: $(a)$ M. Ochiai, K. Miyamoto, T. Kaneaki, S. Hayashi and W. Nakanishi, Science, 2011, 332, 448; (b) K. Maruoka, Angew. Chem., Int. Ed., 2013, 52, 8657; (c) A. P. Antonchick and L. Burgmann, Angew. Chem., Int. Ed., 2013, 52, 3267; (d) Y. Zhao, W. L. Yim, C. K. Tan and Y.-Y. Yeung, Org. Lett., 2011, 13, 4308; (e) Y. Kita, ChemCatChem, 2014, 6, 76.

11 For selected reviews on hypervalent iodine chemistry: $(a)$ V. V. Zhdankin and P. Stang, Chem. Rev., 2002, 102, 2523; (b) H. Tohma and Y. Kita, Adv. Synth. Catal., 2004, 346, 111; (c) R. Narayan, S. Manna and A. P. Antonchick, Synlett, 2015, 26, 1785.

12 A. Sharma and J. F. Hartwig, Nature, 2015, 517, 600.

13 For a Mn-based catalytic system that uses $\mathrm{NaN}_{3}$ as an azido source and $\mathrm{PhIO}$ as an oxidant to achieve the azidation of $3^{\circ}$ and unactivated $2^{\circ} \mathrm{C}-\mathrm{H}$ bonds of drug molecules at $\mathrm{rt}$ : X. Huang, T. M. Bergsten and J. T. Groves, J. Am. Chem. Soc., 2015, 137, 5300.

14 For two recent examples of transition-metal-free aliphatic $\mathrm{C}-\mathrm{H}$ azidation reactions: (a) X. Zhang, H. Yang and P. Tang, Org. Lett., 2015, 17, 5828; (b) S. Kamijo, M. Watanabe, K. Kamijo, K. Tao and T. Murafuji, Synthesis, 2015, 48, 115.

15 (a) Y. Feng and G. Chen, Angew. Chem., Int. Ed., 2010, 49, 958; (b) G. He, S.-Y. Zhang, W. A. Nack, R. Pearson, J. Rabb-Lynch and G. Chen, Org. Lett., 2014, 16, 6488.

16 For selected reviews on visible light-promoted organic reactions: (a) J. M. R. Narayanam and C. R. J. Stephenson, Chem. Soc. Rev., 2011, 40, 102; (b) T. P. Yoon, M. A. Ischay and J. N. Du, Nat. Chem., 2010, 2, 527; (c) C. K. Prier, D. A. Rankic and D. W. C. MacMillan, Chem. Rev., 2013, 113, 5322; (d) J. Xie, H. Jin, P. Xu and C. Zhu, Tetrahedron Lett., 2014, 55, 36.

17 Our light-promoted $\mathrm{C}-\mathrm{H}$ azidation reactions showed similar selectivity and reactivity to Hartwig's Fe-catalyzed reaction system (ref. 12).

18 Synthetically useful aliphatic $\mathrm{C}-\mathrm{H}$ chlorination reactions suitable for complex substrates are still limited. These $3^{\circ}$
$\mathrm{C}-\mathrm{H}$ selective reactions provide a valuable complement to Groves' Mn-catalyzed $2^{\circ} \mathrm{C}-\mathrm{H}$ selective chlorination: (a) W. Liu and J. T. Groves, J. Am. Chem. Soc., 2010, 132, 2010; (b) W. Liu and J. T. Groves, Acc. Chem. Res., 2015, 48, 1727. 19 Intermolecular selective aliphatic $\mathrm{C}-\mathrm{H}$ bromination reactions using a complex substrate as the limiting reagent are still limited. These $3^{\circ} \mathrm{C}-\mathrm{H}$ bromination reactions provide a useful complement to Alexanian's visible-light promoted $2^{\circ} \mathrm{C}-\mathrm{H}$ selective bromination using $\mathrm{N}$ bromoamide reagents: V. A. Schmidt, R. K. Quinn, A. T. Brusoe and E. J. Alexanian, J. Am.Chem. Soc., 2014, 136, 14389.

20 Similar iodination and fluorination reactions with nucleophilic iodide and fluoride additives have been unsuccessful by far. See ref. 4 for the recent success of light-facilitated aliphatic $\mathrm{C}-\mathrm{H}$ fluorination. For the acetoxyiodane-mediated $\quad 2^{\circ} \quad \mathrm{C}-\mathrm{H} \quad$ iodination of hydrocarbons (used as co-solvent): J. Barluenga, E. CamosGomez, D. Rodriguez, F. Gonzalez-Bobes and J. M. Gonzalez, Angew. Chem., Int. Ed., 2005, 44, 5851.

21 For an excellent paper characterizing chain processes in visible light photoredox catalysis based on the measurements of quantum yield $\Phi$ : M. A. Crismesia and T. P. Yoon, Chem. Sci., 2015, 6, 5426. A reaction with $\Phi \gg$ 1 could only be consistent with a product-forming chain mechanism. Our "light/dark" experiment (see ESI $\dagger$ ) showed that the same $\mathrm{C}-\mathrm{H}$ azidation reaction requires constant irradiation for product formation, which suggests a relatively short lifetime of the radical chain process.

22 Z. B. Alfassi and R. H. Shuler, J. Phys. Chem., 1985, 89, 3359. 23 The mechanism of $\mathrm{H}$-abstraction using the iodanyl radical I has been proposed in a number of previous studies, see: $(a)$ ref. 8 and $10 e$; (b) M. Ochiai, T. Ito, H. Takahashi, A. Nakanishi, M. Toyonari, T. Sueda, S. Goto and M. Shiro, J. Am. Chem. Soc., 1996, 118, 7716.

24 For the related light-induced activation of hydroxybenziodoxole to form the iodanyl radical I, see: H. Huang, G. Zhang, L. Gong, S. Zhang and Y. Chen, J. Am. Chem. Soc., 2014, 136, 2280.

25 The synthesis of chloroiodane 31 was recently reported by Togni as an intermediate in the preparation of the corresponding trifluoromethyl aryliodonium compound. V. Matoušek, E. Pietrasiak, R. Schwenk and A. Togni, J. Org. Chem., 2013, 78, 6763. Its use for $\mathrm{C}-\mathrm{H}$ functionalization reactions was unknown.

26 Reaction of 32 with 2 equiv. of 31 and 0.2 equiv. of benzoyl peroxide in HFIP at either $\mathrm{rt}$ or $80{ }^{\circ} \mathrm{C}$ gave no chlorinated product $\mathbf{2 0 .}$ 